\title{
Bow Hunter Syndrome Treated Via an Anterior Approach and Selective Decompression Only
}

\author{
Jung Hoon Kang1, Soo Bin Im*1, Je Hoon Jeong ${ }^{1}$, Dong Seong Shin ${ }^{1}$, Sang Mi Yang ${ }^{1}$ and Jong Hyeon Mun² \\ ${ }^{1}$ Depertment of Neurosurgery, Soonchunhyang University College of Medicine, Republic of korea \\ ${ }^{2}$ Kwangju Christian Hospital, Republic of korea
}

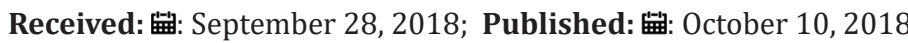

*Corresponding author: Soo Bin Im MD, Department of Neurosurgery, Soonchunhyang University Bucheon Hospital 170, Republic of Korea

\begin{abstract}
We present the case of a 38-year-old male who complained of repeated dizziness and syncope. Bow hunter syndrome (BHS) was diagnosed via computed tomography angiography (CTA) and three-position digital subtraction angiography (DSA). In the neutral position, CTA and DSA revealed left vertebral artery (VA) stenosis at the C2 transverse foramen and right VA hypoplasia. When the head was turned to the right, DSA showed that blood flow decreased at the C3-4 level and stopped at the C2 level. The bony structure around the VA at the C2 transverse foramen was decompressed via an anterior surgical approach, and the symptoms resolved. This case indicates that the stenotic point associated with BHS should be determined its exact stenotic point and surgical treatment should be individualized based on the stenotic point.
\end{abstract}

Keywords: Bow Hunter Syndrome; Rotational Vertebral Artery Syndrome; Anterior Decompression; Posterior Circulation Infarction; Nystagmus; Video nystagmography

Abbreviations: BHS: Bow Hunter Syndrome; BPPV: Benign Paroxysmal Positional Vertigo; CTA: Computed Tomography Angiography; DSA: Digital Subtraction Angiography; VA: Vertebral Artery; VNG: Video Nystagmo Graphy

\section{Introduction}

Dizziness triggered by rotating the head is a characteristic symptom of BHS. However, dizziness has many causes, and patients who complain of dizziness provoked by rotating the head should also be evaluated in terms of a peripheral disorder, such as benign paroxysmal positional vertigo (BPPV). General nystagmus and videonystagmography (VNG) are useful to rule out a peripheral disorder, allowing BHS diagnosis via identification of the characteristic nystagmus [1,2]. There are various treatment options, ranging from conservative treatment such as rehabilitation to surgery [3]. Decompression without fusion is the recommended first-line therapy [4], but the optimal method of VA decompression remains controversial. Although a posterior approach is generally preferred to decompress the VA at the C1-C2 level [4-6], Seki et al. described successful decompression of the $\mathrm{C} 2$ transverse foramen via an anterior approach. We present a case of BHS diagnosed via VNG, CTA and three-position DSA. The exact stenotic point was determine based on three-position DSA. The patient was treated via anterior VA decompression at the C2 transverse foramen, and a satisfactory outcome was achieved.

\section{Case Description}

A 38-year-old male suffering from alcoholism visited our outpatient department complaining of repeated dizziness and a buzzing sound in the left ear. His first ear symptom was a hearing difficulty commencing 1 year prior. Dizziness and a buzzing sound developed when he turned his head to the right, commencing a few months prior. Sometimes, the dizziness was so severe that he could not open his eyes. Then, he failed to maintain balance and fell, losing consciousness for 3-4 seconds. On examination, we found that the symptoms appeared only when he turned the head to the right, whether he was standing, sitting, or lying. No symptoms were evident when the head was rotated to the left or in the neutral position. A down-beat nystagmus appeared when the head turned to the right. A left-ear hearing reduction and left-side, central facial palsy of House-Brackmann grade 2 were evident, as was a slight tremor of the right lower extremity.

We used VNG to determine whether the problem was peripheral or central. VNG revealed right- beating nystagmus with a downbeat component when the head was turned to the right (Figure 1), indicating a central rather than a peripheral origin.

We scheduled brain and neck CTA, brain MRI, and three-position DSA. CTA revealed a hypoplastic right VA and left VA stenosis at the lateral curvature of the VA just below the $\mathrm{C} 2$ transverse foramen. Brain MRI revealed a tiny, acute ischemic infarction in the right cerebellum. DSA was performed in three positions (with the head neutral, $90^{\circ}$ to the left, and $90^{\circ}$ to the right). In the neutral position, left VA stenosis was observed just below the $\mathrm{C} 2$ transverse 
foramen, as on CTA. Notably, when the head was turned to the left, the VA stenotic lesion became wider than in the neutral position. When the head was turned to the right, the blood flow tapered at the C3-4 level and was totally occluded at the C2 level (Figure 2). Immediately after angiography with $90^{\circ}$ to the right, the patient loosed consciousness and DSA was halt. As the right VA was hypo- plastic and flow almost absent, the posterior circulation was highly dependent on the left VA. We concluded that the left VA became kinked just below the entry point of the $\mathrm{C} 2$ transverse foramen when the head was turned to the right. We decided to perform surgical decompression of the left VA.

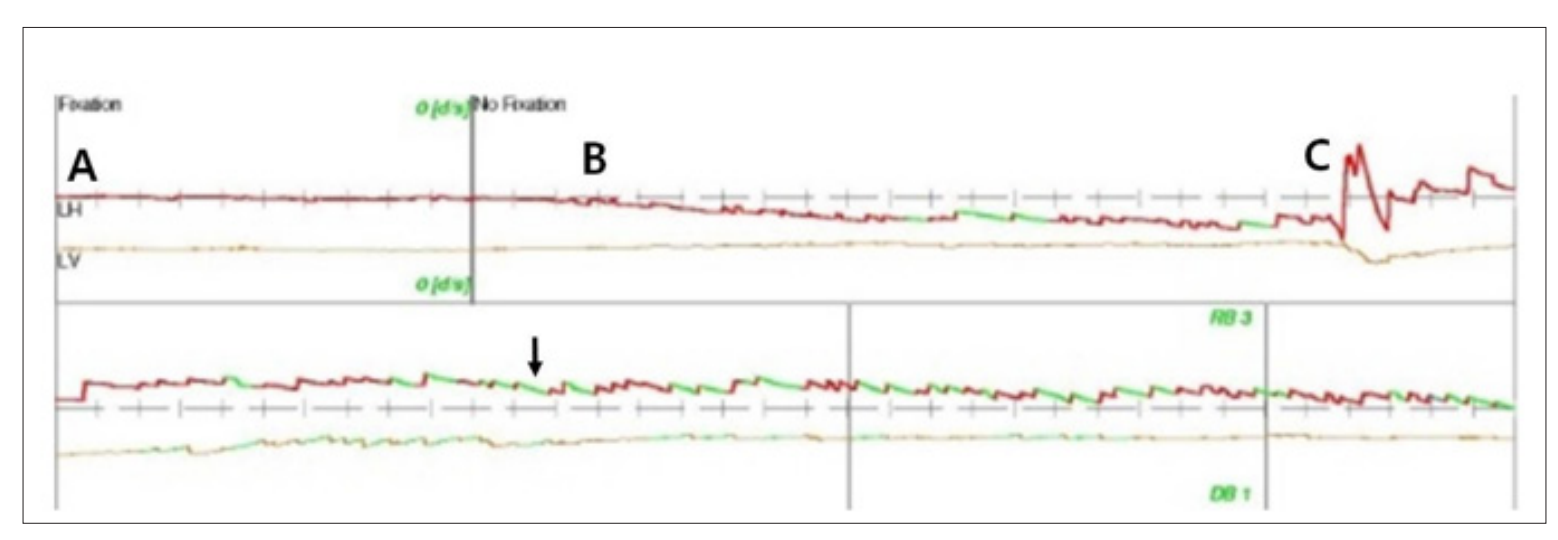

Figure 1: Videonystagmography (VNG) revealed no nystagmus in the neutral position (A) or when the head was turned to the left (B). Right-beating nystagmus (A) with a down-beat component was observed when the head was turned to the right.

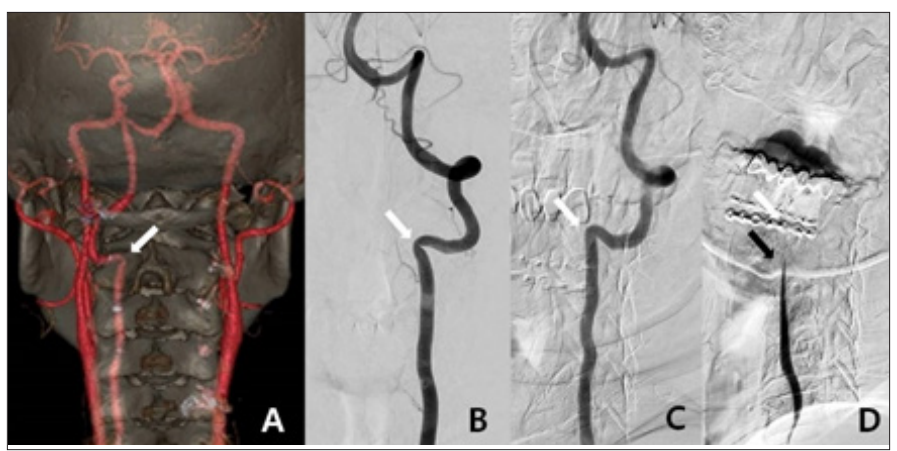

Figure 2: A. The posteroanterior view of 3D-reconstruction CT angiography revealed left VA stenosis at the C2 transverse foramen (white arrow). B. The anteroposterior view of left VA angiography with the head in the neutral position revealed left VA stenosis at the C2 transverse foramen (white arrow). C. The lateral view of left VA angiography when the head was turned to the left revealed that the stenotic VA at $\mathrm{C} 2$ became wider than in the neutral position. D. The lateral view of left VA angiography when the head was turned to the right showed that blood flow decreased at the C3-4 level (black arrow) and stopped at the C2 level (white arrow).

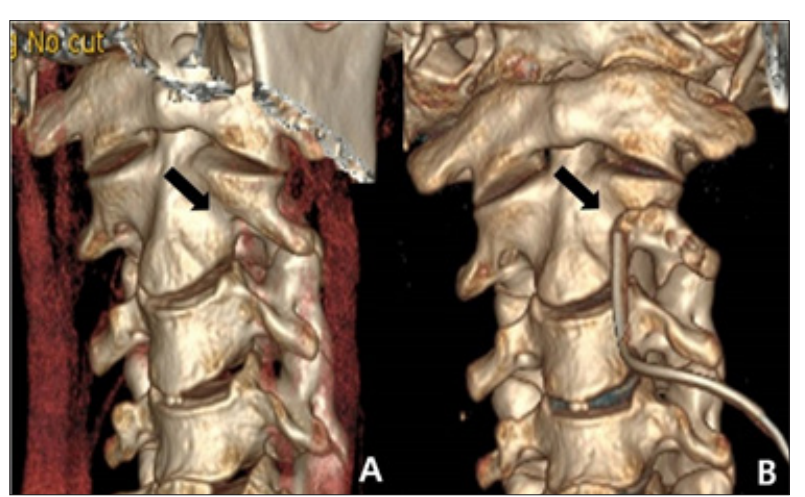

Figure 3: A. Preoperative CT 3D-reconstruction image. B. The postoperative CT 3D-reconstruction image showed that the anterior portion of the transverse foramen had been removed; the foramen was thus widened while preserving the articular facet (black arrow). 
The patient was placed in the supine position with his head slightly extended via Holter traction. A transverse skin incision was created on the medial border of the sternocleidomastoid muscle at the C2-3 level. After dissecting the prevertebral muscles, the $\mathrm{C} 2$ vertebral body, left transverse process, and left VA were exposed. The anterolateral portion of the left transverse foramen that covered the VA was carefully drilled. The bony spicule at the lateral curvature of the VA just below the $\mathrm{C} 2$ transverse process was also removed. The anterior half of the bony structure surrounding the VA was fully decompressed, and VA pulsation immediately became more active. Postoperative CTA showed a wider transverse foramen than preoperatively (Figure 3). The symptoms improved dramatically after surgery. Neck movement was not limited, and no cervical spine instability was evident on a dynamic X-ray.

\section{Discussion}

It is challenging to distinguish between nystagmus of peripheral and central origin; this requires consideration of various clinical symptoms and features. The direction of nystagmus after a positioning maneuver can point to a central disorder. Paroxysmal down-beat, up-beat, or pure torsional nystagmus is considered to reflect a central origin [7]. BHS-associated nystagmus is mostly down-beat, with both horizontal and torsional components toward the side of the compressed VA. Two explanations have been advanced. Compression of the dominant VA triggers acute bilateral vertebrobasilar insufficiency, but asymmetric ischemia of the superior labyrinth causes down-beating nystagmus. Similarly, inferior cerebellar infarction in a unilateral posterior inferior cerebellar artery triggers nystagmus with an ipsilateral horizontal component [2]. Our patient's nystagmus contained a down-beat component, and thus was not exclusively right-beating, suggesting a central origin. We suspected BHS of central origin because the symptoms were similar to those of nystagmus seen in BHS and suggestive of BHS. Therefore, we proceeded to a vascular evaluation including CTA, MRI and three-position DSA.

Rotatory VA stenosis at the $\mathrm{C} 1-\mathrm{C} 2$ level with reduced blood flow can be observed in normal individuals, reflecting relative immobilization of the VA at the C2 and C1 transverse foramina. During head rotation, the atlantoaxial joint is fixed, whereas the C1 contralateral transverse foramen moves forward and downward, kinking the contralateral VA at the transverse foramen and stretching the extraspinal VA segment, decreasing blood flow $[8,9]$. This does not normally trigger infarction of the posterior circulation because the remaining contralateral VA and the anastomosis confer adequate circulation [10]. If the opposite VA is hypoplastic or rendered stenotic or occlusive by arteriosclerotic changes, the posterior circulation is vulnerable to infarction in most BHS cases [3]. In the case reported here, as the right VA was hypoplastic and flow almost absent, the posterior circulation was highly dependent on the left VA. We concluded that when the head was turned right the left VA became kinked just below the entry point of the C2 transverse foramen.

Matsuyama et al. [6] compared C1-C2 fusion with posterior VA decompression. Fusion reduced the range of head rotation but eliminated the risk of re-stenosis. VA decompression did not restrict head movement, but at a risk of re-stenosis. Lu et al. [5] suggested that posterior decompression should be used to treat VA occlusion at $\mathrm{C} 3$ and above, and anterior decompression to treat occlusion between C4 and C6. Zaidi et al. [4] considered that the anatomical course of the VA was the most important factor when choosing an approach. The VA moves anteriorly from C6 to C3 after passing the lateral curvature at $\mathrm{C} 2$, and then ascends sharply posteriorly. The VA at C1-C2 is best visualized via a posterior approach, and below C3 via an anterior approach. Decompression without fusion is recommended as first-line therapy; decompression is associated with a low restenosis rate and preservation of full-range neck motion. Seki et al. [11] successfully used anterior decompression to treat an BHS case with an occlusion at the C2 transverse foramen, removing the anterior portion of this foramen and the external onethird of the superior articular process to untether the VA. However, we chose an anterior approach because the stenotic lesion lay just below the $\mathrm{C} 2$ transverse foramen, not in the C1-2 joint, and favoured an anterior approach. If the BHS is not associated with C1-2 joint via detailed stenotic point evaluation, we can avoid posterior instrumentation that may cause severe limitation of neck motion. Upper cervical instability was of concern; we preserved the disc space and the articular joint. We obtained adequate VA exposure without violating the joint or disc space.

\section{Conclusion}

A patient with repeated dizziness and syncope was diagnosed with BHS and treated via selective anterior VA decompression at the precise point of stenosis, which was identified using three-position DSA. This case indicates that the BHS should be determined its exact stenotic point and surgical treatment should be individualized based on the stenotic point

\section{References}

1. Mekki S (2014) The role of video nystagmography (VNG) in assessment of a dizzy patient. The Egyptian Journal of Otolaryngology 30(2): 69.

2. Choi KD, Choi JH, Kim JS, Kim HJ, Kim MJ, et al. (2013) Rotational vertebral artery occlusion: mechanisms and long-term outcome. Stroke 44(7): 1817-1824.

3. Duan G, Xu J, Shi J, Cao Y (2016) Advances in the pathogenesis, diagnosis and treatment of Bow Hunter's Syndrome: a comprehensive review of the literature. Interv Neurol 5(1-2): 29-38.

4. Zaidi HA, Albuquerque FC, Chowdhry SA, Zabramski JM, Ducruet AF, et al. (2014) Diagnosis and management of bow hunter's syndrome: 15year experience at Barrow Neurological Institute. World Neurosurg 82(5): 733-738.

5. Lu DC, Zador Z, Mummaneni PV, Lawton MT (2010) Rotational vertebral artery occlusion-series of 9 cases. Neurosurgery 67(4): 1066-1072.

6. Matsuyama T, Morimoto T, Sakaki T (1997) Comparison of C1-2 posterior fusion and decompression of the vertebral artery in the treatment of bow hunter's stroke. J Neurosurg 86 (4):619-623.

7. U Büttner CHTB (2009) Diagnostic criteria for central versus peripheral positioning nystagmus and vertigo: a review. Acta Oto-Laryngologica 119(1): $1-5$.

8. Wakayama K, Murakami M, Suzuki M, Ono S, Shimizu N, et al. (2005) Ischemic symptoms induced by occlusion of the unilateral vertebral artery with head rotation together with contralateral vertebral artery dissection- case report. J Neurol Sci 236(1-2): 87-90. 
9. Jost GF, Dailey AT (2015) Bow hunter's syndrome revisited: 2 new cases and literature review of 124 cases. Neurosurg Focus 38(4): E7.

10. Toole JF, Tucker SH (1960) Influence of head position upon cerebral circulation: studies on blood flow in cadavers. AMA Archives of Neurology 2(6): 616-623.

\section{ISSN: 2574-1241}

DOI: 10.26717/BJSTR.2018.09.001870

Soo Bin Im MD. Biomed J Sci \& Tech Res

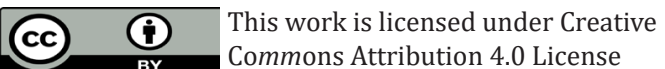

Submission Link: https://biomedres.us/submit-manuscript.php
11. Seki T, Hida K, Akino M, Iwasaki Y (2001) Anterior decompression of the atlantoaxial vertebral artery to treat bow hunter's stroke: technical case report. Neurosurgery 49(6): 1474-1476.

$\begin{array}{ll}\text { BIOMEDICAL } & \text { Assets of Publishing with us } \\ \text { RESEARCHES } & \text { - Global archiving of articles } \\ \text { - Immediate, unrestricted online access } \\ \text { - RsN: 2574-1241 }\end{array}$

